THE production of interferon- $\gamma$ and tumour necrosis factor- $\alpha$ was evaluated in the peripheral blood mononuclear cells (PBMCs) from healthy donors and AIDS patients after Rhodococcus equi infection in vitro. PBMCs from healthy donors secreted elevated levels of IFN- $\gamma$ and TNF- $\alpha$ when challenged in vitro with killed $R$. equi, whereas the release of both cytokines was impaired in supernatant cultures from AIDS patients. We conclude that the failure of IFN- $\gamma$ generation in AIDS patients in response to $R$. equi is not antigen-specific but it may reflect the global impairment of T-cell function. In such patients, however, the infection with $R$. equi, a facultative intracellular pathogen which survives and replicates within macrophages, may be responsible for the impairment in the TNF- $\alpha$ release, possibly enhancing the HIV-induced macrophage dysfunction.

Key words: AIDS, IFN- $\gamma$, In vitro defective production, Rbodococcus equi, TNF- $\alpha$.

\section{Defective production of interferon- $\gamma$ and tumour necrosis factor- $\alpha$ by AIDS mononuclear cells after in vitro exposure to Rhodococcus equi}

\author{
S. Delia, C. M. Mastroianni, ${ }^{\text {CA }}$ M. Lichtner, \\ F. Mengoni, S. Moretti and V. Vullo
}

Department of Infectious and Tropical Diseases, La Sapienza University, Rome, Italy

${ }^{\mathrm{CA}}$ Corresponding Author

\section{Introduction}

Rhodococcus equi, a well-known animal pathogen, has been reported to cause increasingly frequent life-threatening opportunistic infections in patients with AIDS. $^{1}$ Like the mycobacteria, $R$ equi can invade and replicate within infected macrophages. ${ }^{2}$ Several hypotheses have been put forward concerning the survival of $R$. equi within phagocytes and one major pathogenetic mechanism might be its ability to block phagolysosome fusion.

Cell-mediated immunity is considered to be of major importance in resistance to infection. ${ }^{3}$ Because of the intracellular nature of the organism, the immunologic resistance to $R$. equi infection is thought to be mediated by cooperative interaction between $\mathrm{T}$ lymphocytes and macrophages. This interaction probably depends on the interplay of cytokines secreted by lymphocytes and other mononuclear cells. A recent investigation in euthymic mice suggests a role for endogenously generated interferon- $\gamma$ (IFN- $\gamma$ ) and tumour necrosis factor- $\alpha$ (TNF- $\alpha$ ) in host defence against $R$ equi infection. ${ }^{4}$ The cytokines that mediate immunologic resistance to $R$ equi in humans remain undefined.

To gain insight into the pattern of the primarily $\mathrm{T}$ cell- and macrophage-secreted cytokines that contribute to human anti-rhodococcal defences, we evaluated IFN- $\gamma$ and TNF- $\alpha$ production by peripheral blood mononuclear cells
(PBMCs) from healthy donors and AIDS patients in response to $R$. equi stimulation in vitro.

\section{Materials and Methods}

Subjects: Five AIDS patients, hospitalized at the Department of Infectious and Tropical Diseases of La Sapienza University, and six healthy volunteer donors were considered in this study. None of the AIDS patients had evidence of overt opportunistic infections at enrolment.

Bacteria: R. equi reference strain ATCC 33701 was obtained from American Type Culture Collection (Rockville, MD). Bacteria were grown at $38^{\circ} \mathrm{C}$ for $48 \mathrm{~h}$ in brain heart infusion broth, and then suspended in RPMI 1640 (GIBCO, Bio Cult., Paisley, UK). Killed bacteria were obtained by heat-inactivation at $65^{\circ} \mathrm{C}$ for $30 \mathrm{~min}$.

Stimulation of PBMCs with R. equi: PBMCs were obtained from venous blood using anticoagulant acid citrate dextrose blood collection tubes (Becton-Dickinson, San Jose, CA, USA) and isolated by centrifugation with Ficoll-Hypaque (Sigma Chemical Co., St. Louis, MO, USA). ${ }^{5}$ The isolated PBMCs were resuspended in RPMI medium supplemented with $5 \%$ fetal calf serum (FCS) (GIBCO), $2 \mathrm{mM}$ glutamine (GIBCO), penicillin (100 units/ml) and streptomycin (100 $\mathrm{gg} /$ $\mathrm{ml}$ ). Cells were seeded into 24-well macrotitre plates at a concentration of $1 \times 10^{6}$ cells/well 
and suspensions of killed bacteria at a final concentration of $10^{4}-2 \times 10^{6}$ cells $/ \mathrm{ml}$ were added. Control wells contained no bacteria. Plates were then incubated at $37^{\circ} \mathrm{C}$ with $5 \% \mathrm{CO}_{2}$ in a humidified atmosphere and supernatants were harvested after $24 \mathrm{~h}$ for measurement of TNF- $\alpha$ concentrations and after $48 \mathrm{~h}$ for measurement of IFN- $\gamma$ levels. The concentrations of cytokine induced by $R$ equi were calculated as that measured in the appropriate supernatant, minus the cytokine concentration in control wells containing media alone. All supernatants were stored at $-80^{\circ} \mathrm{C}$ before determination of cytokine levels.

Cytokine measurement: TNF- $\alpha$ concentrations were measured by a quantitative immunoenzymatic sandwich assay (Quantikine, R \& D Systems, Minneapolis, MN, USA). Unknown values of TNF- $\alpha$ in the samples were determined by referring to the standard curve and expressed as $\mathrm{pg} / \mathrm{ml}$. The detection limit of the assay was $4.8 \mathrm{pg} / \mathrm{ml}$.

IFN- $\gamma$ concentrations were measured by a commercial sandwich ELISA (human IFN- $\gamma$ ELISA kit; Central Laboratory of Netherlands Red Cross Blood Transfusion Service, Amsterdam). Levels of IFN- $\gamma$ were determined by comparison with a standard curve generated from specimens of known IFN- $\gamma$ concentrations. The detection limit of the assay was $20 \mathrm{pg} / \mathrm{ml}$.
Statistical analysis: Statistical evaluation was performed by one-way analysis of variance.

\section{Results}

The results for IFN- $\gamma$ and TNF- $\alpha$ release by human mononuclear cells in response to stimulation with $R$ equi are summarized in Fig. 1. The levels of IFN- $\gamma$ produced by the cells from healthy donors were significantly greater than that in the AIDS patients (mean \pm S.E.M., $778 \pm 129 \mathrm{pg} / \mathrm{ml}$ and $57.4 \pm 28.6 \mathrm{pg} / \mathrm{ml}$, respectively; $p<0.001$ ). Moreover, $R$ equi was able to induce the production of IFN- $\gamma$ in the supernatants of cell cultures from healthy donors in a dose-dependent manner (Fig. 2). When cells of AIDS patients were stimulated with killed bacteria at a final concentration of $10^{4}-10^{6}$ cells $/ \mathrm{ml}$, no in vitro secretion of IFN- $\gamma$ in supernatants was obtained. In response to $R$ equi at a maximum dose of $2 \times 10^{6}$ cells $/ \mathrm{ml}$, IFN- $\gamma$ was still undetectable in culture supernatants from two AIDS patients.

With regard to TNF- $\alpha$ production, detectable levels of this cytokine were found in all culture supernatants from AIDS patients. However, healthy donors produced three- to fourfold more TNF- $\alpha$, on average, in response to $R$ equi than did the AIDS patients (mean \pm S.E.M., $144 \pm 31$ and $39.7 \pm 15.2$, respectively; $p<0.05$ ) (Fig. 1).
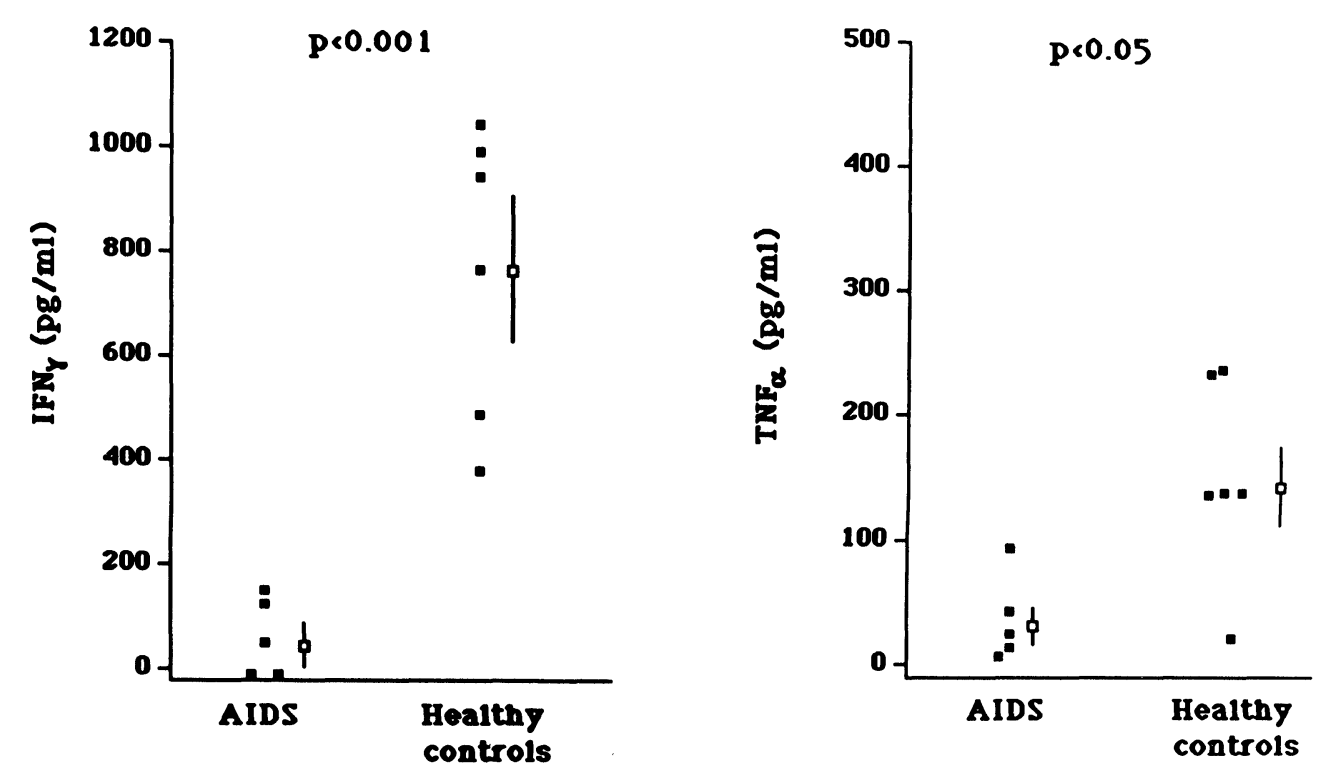

FIG. 1. Concentrations of IFN- $\gamma$ and TNF- $\alpha$ in the supernatants of cell cultures from AIDS patients and healthy controls after stimulation with killed $R$. equi $\left(2 \times 10^{6}\right.$ cells $\left./ \mathrm{ml}\right)$. Vertical bars represent the mean values \pm S.E.M. 


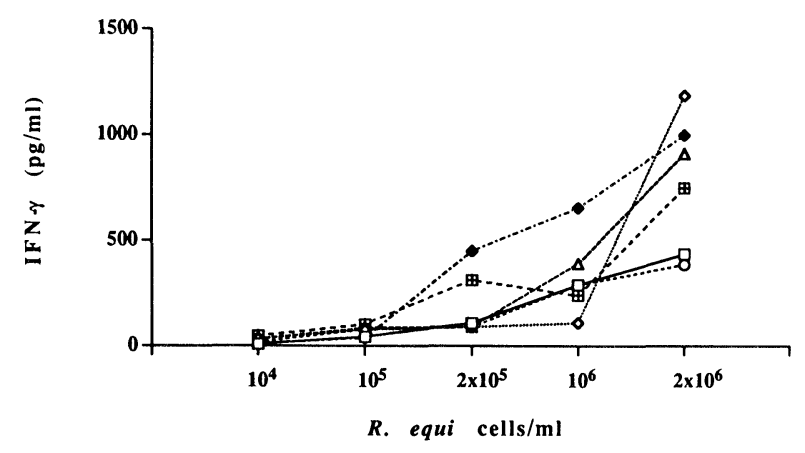

FIG. 2. Dose responses of IFN- $\gamma$ secretion by PBMCs from the six healthy donors after stimulation with different concentrations of killed $R$. equi. Each symbol corresponds to a different individual.

Moreover, no dose-dependent effect on TNF- $\alpha$ release was observed when PBMCs were incubated with different concentrations of bacteria (Fig. 3).

\section{Discussion}

$R$ equi infections in humans are related to the impairment of cell-mediated immune mechanisms involving the T-cell-macrophage system. IFN- $\gamma$ and TNF- $\alpha$ are two cytokines which have been reported to be involved in human cell-mediated immunity to infection with intracellular pathogens. ${ }^{6,7}$ The results of the present study indicate that PBMCs from healthy human donors that were stimulated in vitro with killed $R$. equi secreted high levels of IFN- $\gamma$. Moreover, IFN- $\gamma$ release was dose-dependent with respect to the concentration of the bacterial suspension in the culture medium. In contrast, the production of IFN- $\gamma$ was strongly impaired in supernatants of $R$ equi-stimulated cultures from AIDS patients. These findings are

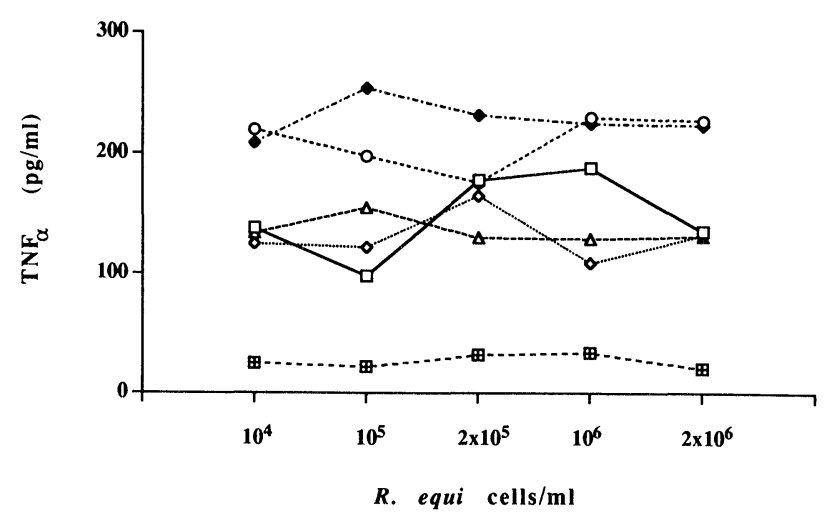

FIG. 3. TNF- $\alpha$ production by PBMCs from the six healthy donors after stimulation with different concentrations of killed $R$. equi. Each symbol corresponds to a different individual. consistent with previous investigations which have demonstrated that the mononuclear cells from patients with AIDS are defective in their ability to release IFN- $\gamma$ in response to various microbial antigens. ${ }^{8}$ Since IFN- $\gamma$ plays an essential role in the activation of macrophages contributing to enhancing their activity against microbial challenge, the defect in IFN- $\gamma$ release represents a critical immunologic alteration that predisposes AIDS patients to infections with opportunistic intracellular pathogens. In such patients, the failure of IFN- $\gamma$ generation reflects the global impairment of T-cell function. On the other hand, in HIV-seronegative patients with certain infectious diseases, such as leprosy, leishmaniosis, tuberculosis and filariasis, the in vitro defect in antigen-induced IFN- $\gamma$ production is not generalized but is restricted to the infecting pathogen alone and probably renders these subjects deficient in their individual T-cell responsiveness to their own progressive intracellular infection. ${ }^{9}$ To date, there is no evidence that in human rhodococcal disease the impairment of in vitro $R$ equi-induced IFN- $\gamma$ production is antigen-specific and may be limited to the inability of T-cells to respond to $R$ equi alone.

Our in vitro experiments demonstrated also that TNF- $\alpha$, a primarily macrophage-secreted cytokine, seems to be involved in the immunologic response to $R$ equi infection. Indeed, PBMCs from healthy donors produced elevated levels of TNF- $\alpha$ when challenged in vitro with $R$. equi. These findings are in agreement with the results of Nordamann et al. ${ }^{4}$ who have demonstrated that, in a murine model, splenic cells of uninfected euthymic mice produced, in vitro, greater amounts of TNF- $\alpha$ when incubated with R. equi.

On the other hand, PBMCs from AIDS patients released very little TNF- $\alpha$ in the supernatants in response to $R$ equi infection in vitro. The production of TNF- $\alpha$ in AIDS patients has been widely investigated with different results. Amman et al. ${ }^{10}$ reported that PBMCs from AIDS or AIDS related complex patients were deficient in their inability to produce TNF$\alpha$ in comparison to normal controls. In contrast, Molina et al. ${ }^{11}$ have demonstrated that, after stimulation with endotoxin, HIV-infected mononuclear cells produce amounts of TNF- $\alpha$ comparable to that of uninfected cells. Similar results were reported by Chehimi and $\mathrm{CO}^{-}$ workers $^{12}$ who showed that when PBMCs from HIV-infected individuals and uninfected control donors are stimulated in vitro, they produce equivalent levels of TNF- $\alpha$.

In the present study, the TNF- $\alpha$ released by 
$R$ equi-infected PBMCs from AIDS patients was significantly less than that seen in normal controls, suggesting that in vitro infection with $R$ equi may affect the production of this cytokine in mononuclear cells harvested from patients with AIDS. As reported for disseminated Mycobacterium avium-intracellulare complex disease, it is conceivable that $R$ equi infection in AIDS patients may contribute to the aggravation of HIV-induced macrophage dysfunction which leads to the impairment of TNF- $\alpha$ release. $^{13}$

On the other hand, it cannot be excluded that the reduced secretion of TNF- $\alpha$ may depend on differences in the virulence of $R$. equi. In our experiments, the production of TNF- $\alpha$ by $R$ equi-infected mononuclear cells was evaluated after stimulation with the strain ATCC 33701, a $R$ equi strain which was previously demonstrated to be virulent in vivo in both mice and horses. ${ }^{14}$ Moreover, it has been reported that this virulent strain had the capacity to survive and replicate within macrophages in vitro, whereas avirulent strains were unable to efficiently replicate within macrophages. ${ }^{15}$ In this respect, the intracellular growth of virulent $R$. equi may decrease the viability of HIV-infected macrophages and cause them to become unable to produce TNF- $\alpha$ in vitro. Further studies will be done to assess the effect of TNF- $\alpha$ in rhodococcal growth in macrophages from AIDS patients with and without $R$. equi infection.

\section{References}

1. Drancourt M, Bonnet E, Gallais H, Peloux Y, Raoult D. Rbodococcus equ infection in patients with AIDS. J Infection 1992; 24: 123-131.

2. Prescott JF. Rbodococcus equi: an animal and human pathogen. Clin Microbiol Rev 1991; 4: 20-34.

3. Nordmann P, Ronco E, Nauciel C. Role of T-lymphocyte subsets in Rbodococcus equi infection. Infect Immun 1992; 60: 2748-2752

4. Nordmann P, Ronco E, Guenounou M. Involvement of interferon $\gamma$ and tumour necrosis factor- $\alpha$ in host defense against Rbodococcus equi. $J$ Infect Dis 1993; 167: 1456-1459.

5. Boyum A. Ficoll-Hypaque method for separating mononuclear cells from human blood. Clin Lab Invest 1968; 21(suppl 97): 77-89.

6. Murray EW. Gamma-interferon, cytokine-induced macrophage activation, and antimicrobial host defense: in vitro, in animal models, and in humans. Diagn Microbiol Infect Dis 1990; 13: 411-421.

7. Murray HW. Interferon-gamma and host antimicrobial defense: current and future clinical applications. Am J Med 1994; 97: 459-467.

8. Murray EW, Rubin BY, Masur H, Roberts RB. Impaired production of lymphokines and immune (gamma) interferon in the acquired immunodeficiency syndrome. $N$ Engl J Med 1984; 310: 883-889.

9. Murray EW. Interferon-gamma, the activated macrophage, and host defense against microbial challenge. Ann Inter Med 1988; 108: 595-608.

10. Amman AJ, Palladino MA, Volberding P, Abram D, Martin NL, Connant M. Tumor necrosis factor $\alpha$ and $\beta$ in acquired immunodeficiency syndrome (AIDS) and AIDS-related complex. J Clin Immunol 1987; 7: 481-485.

11. Molina JM, Schindler R, Ferrari R, et al. Production of cytokines by peri pheral blood monocytes/macrophages infected with human immunodeficiency virus type 1 (HIV-1). J Infect Dis 1990; 161: 888-893.

12. Chehimi BJ, Starr SE, Frank I, et al. Impaired interleukin 12 production in human immunodeficiency virus-infected patients. J Exp Med 1994; 179: 1361-1366.

13. Sathe SS, Sarai A, Tsigler D, Nedunchezian D. Pentoxifylline aggravates impairment in tumor necrosis factor- $\alpha$ secretion and increases mycobacterial load in macrophages from AIDS patients with disseminated Mycobacterium avium-intracellulare complex infection. $J$ Infect Dis 1994; 170: 484-487.

14. Takai S, Sekizaki T, Ozawa T, Suguwara T, Watanabe Y, Tsubaki S Association between a large plasmid and 15- to 17-kilodalton antigens in virulent Rbodococcus equi. Infect Immun 1991; 59: 4056-4060.

15. Hondalus MY, Mosser DM. Survival and replication of Rbodococcus equi in macrophages. Infect Immun 1994; 62: 4167-4175.

Received 5 April 1995;

accepted in revised form 22 May 1995 


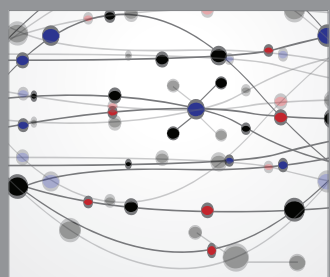

The Scientific World Journal
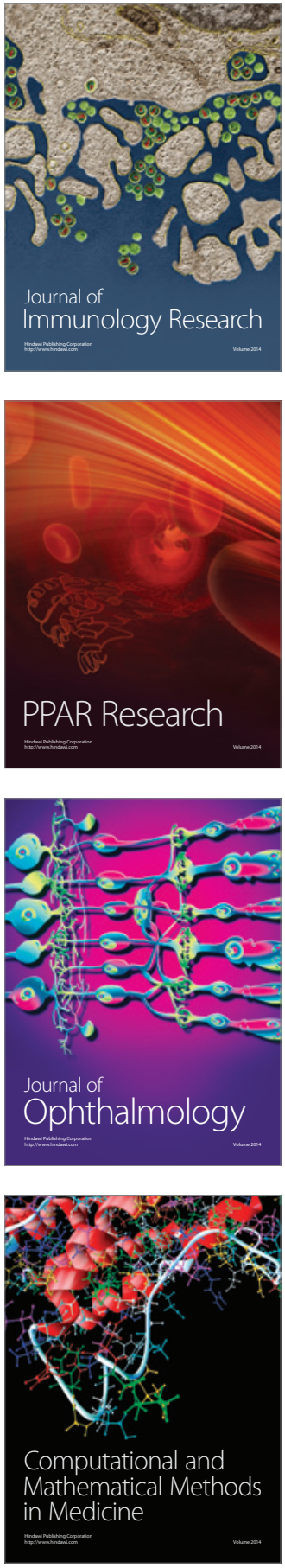

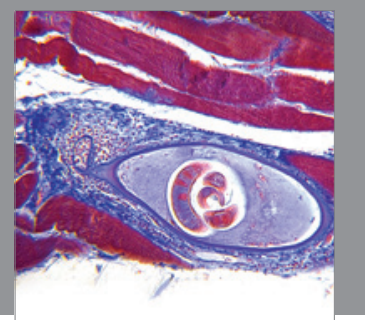

Gastroenterology

Research and Practice
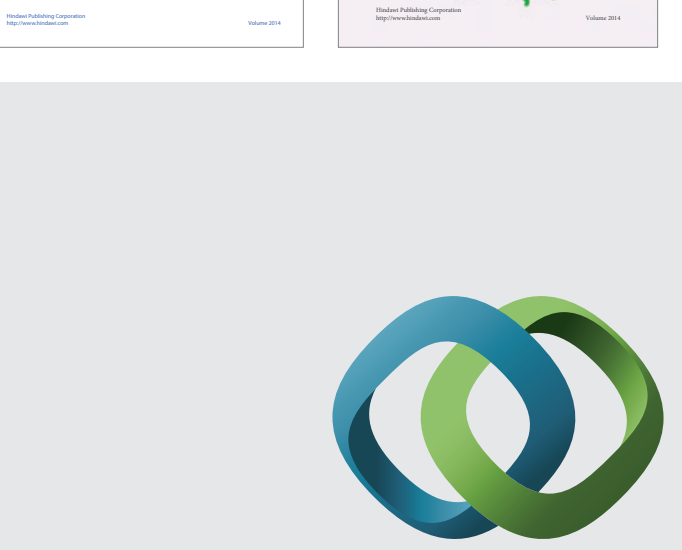

\section{Hindawi}

Submit your manuscripts at

http://www.hindawi.com
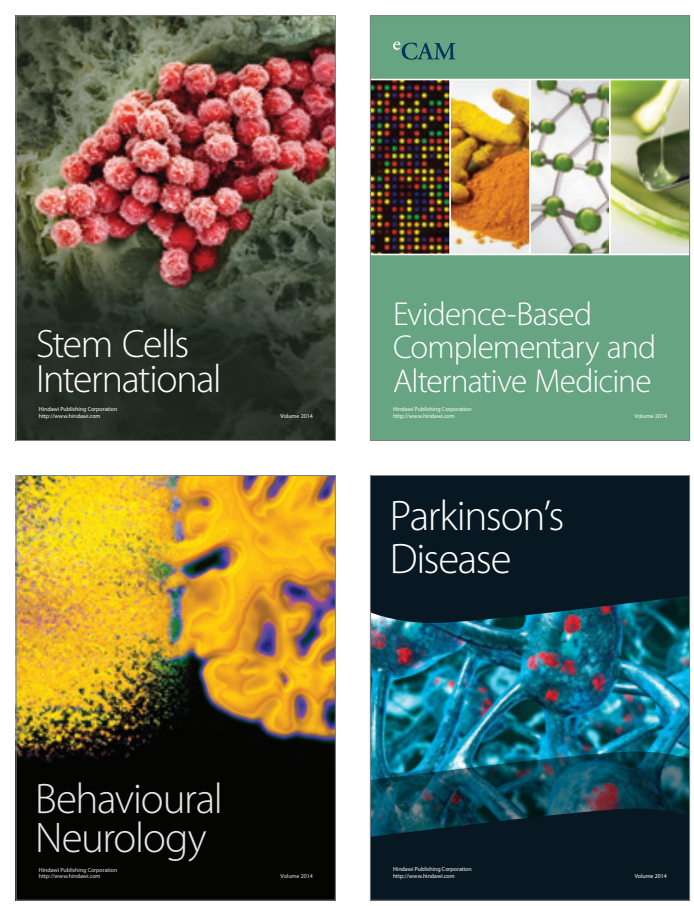

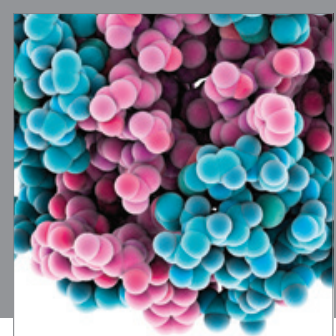

Journal of
Diabetes Research

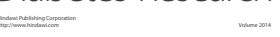

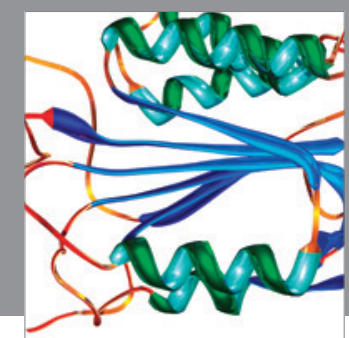

Disease Markers
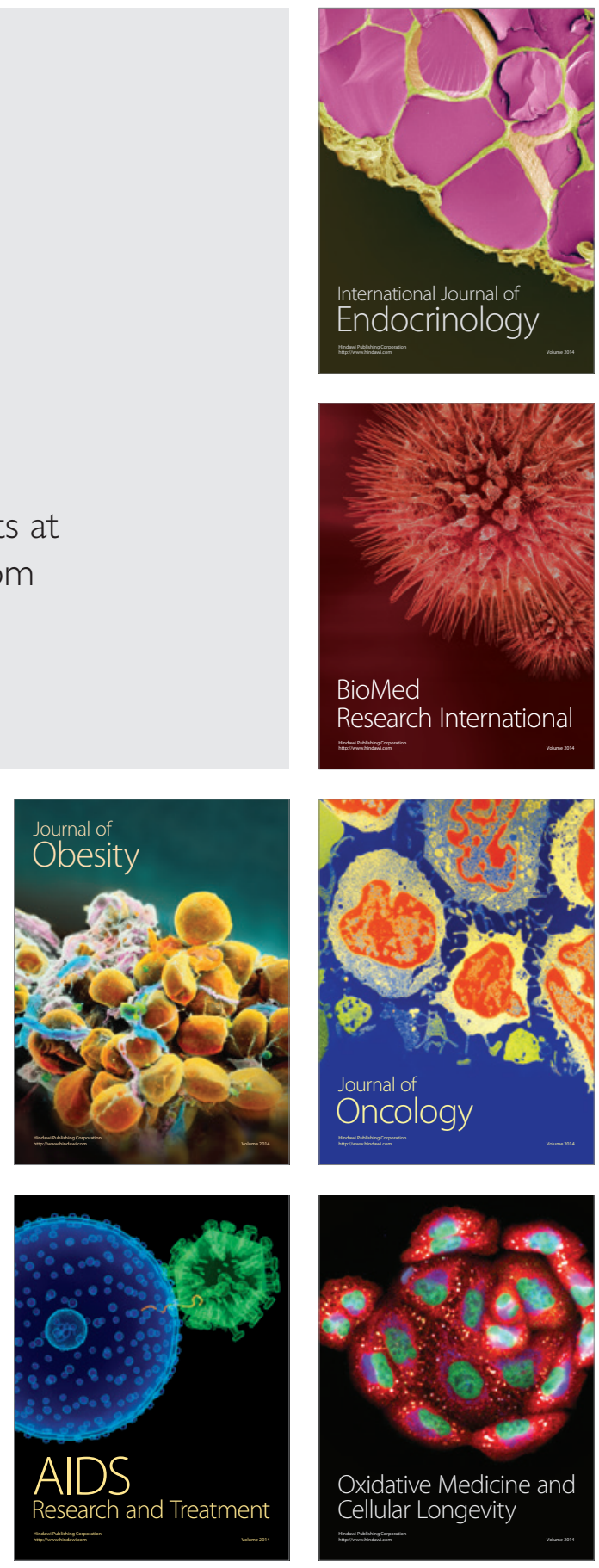